\title{
Eurofusion-DEMO Divertor - Cassette Design and Integration
}

Giuseppe Mazzone ${ }^{\mathrm{a}^{*}}$, Jeong-Ha You ${ }^{\mathrm{b}}$, Christian Bachmann ${ }^{\mathrm{c}}$, Ugo Bonavolontà $^{\mathrm{d}}$, Valerio Cerri ${ }^{\mathrm{a}}$, Domenico Coccorese $^{\mathrm{d}}$, Danilo Dongiovanni ${ }^{\mathrm{a}}$, Davide Flammini ${ }^{\mathrm{a}}$,Paolo Frosi ${ }^{\mathrm{a}}$, Laurent Forest ${ }^{\mathrm{g}}$, Giuseppe Di Gironimo ${ }^{\mathrm{d}}$, Gennaro Di Mambro ${ }^{\mathrm{e}}$, Vito Imbriani ${ }^{\mathrm{d}}$, Antonio Maffucci ${ }^{\mathrm{e}}$, Domenico Marzullo $^{\mathrm{d}}$, Pietro Alessandro Di Maio ${ }^{\mathrm{f}}$, Maria Teresa Porfiri ${ }^{\mathrm{a}}$, Eugenio Vallone ${ }^{\mathrm{f}}$, Rosaria Villari ${ }^{\mathrm{a}}$, Eliseo Visca ${ }^{a}$, Christian Vorpahl $^{\mathrm{c}}$

\author{
${ }^{a}$ ENEA, Department of Fusion and Technology for Nuclear Safety and Security, Frascati, Italy \\ ${ }^{b}$ Max Planck Institute of Plasma Physics, Boltzmann Str. 2, 85748 Garching, Germany \\ ${ }^{c}$ EUROfusion, PMU-PPPT, Boltzmann Str. 2, 85748 Garching, Germany \\ ${ }^{d}$ CREATE/University of Naples, Industrial Engineering, Piazzale Tecchio 80, 80125 Napoli, Italy \\ ${ }^{e}$ CREATE - University of Cassino and Southern Lazio, Via G. Di Biasio 43, 03043 Cassino, Italy \\ ${ }^{f}$ Department of Engineering, University of Palermo, Viale delle Scienze, Ed. 6, 90128 Palermo, Italy \\ ${ }^{g}$ CEA-DEN-Service d'études mécaniques et thermiques (SEMT), CEA, Université Paris-Saclay, F-91191 Gif sur Yvette,
} France

The Eurofusion-DEMO design will complete the Pre Conceptual Design phase (PCD) with a PCD Gate, named G1, scheduled to take place in Q4 2020 that will focus on assessing the feasibility of the plant and its main components prior to entering into the Conceptual Design phase. In the paper first an overview is given of the Eurofusion-DEMO Divertor Assembly including design and interface description, systems and functional requirements, load specification, system classification, manufacturing procedures and cost estimate. Then critical issues are discussed and potential design solutions are proposed, e.g.:

- Neutron material damage limits of the different (structural) materials present in the divertor assembly (as $\mathrm{CuCrZr}$, Eurofer) and in the vacuum vessel (AISI $316 \mathrm{~L}(\mathrm{~N})-\mathrm{IG})$;

- Temperature hot spots in parts of the divertor assembly exposed to high nuclear heating and high heat radiation (from the plasma core or the separatrix) causing difficulties for active or passive cooling (e.g. cassette body structure, liner support structures, mechanical supports, divertor toroidal rails);

- Arrangement and design of plasma-facing components and liner with pumping slot in the divertor cassette to enable pumping of exhaust gases from the lower port.

\section{Introduction}

In the frame of the EU fusion roadmap activity Horizon 2020 [2][3] the Pre Conceptual Design phase (PCD) of DEMOnstration Fusion Power Plant (DEMO) has been launched by the EUROfusion Consortium. The PCD will complete with a PCD Gate Review, named G1, scheduled to take place in Q4 2020 [4]. Table 1 reports the main DEMO parameters, compared with the ones of ITER reactor used as reference.

Table 1. DEMO main parameters. Comparison with ITER

\begin{tabular}{cccc}
\hline & & DEMO & ITER \\
\hline Major radius & $R(\mathrm{~m})$ & 8.94 & 6.20 \\
\hline Minor radius & $a(\mathrm{~m})$ & 2.88 & 2.00 \\
\hline Toroidal field & $B_{\mathrm{t}}(\mathrm{T})$ & 4.89 & 5.30 \\
\hline Plasma current & $I_{\mathrm{P}}(\mathrm{MA})$ & 19.07 & 15.0 \\
\hline Elongation & $k$ & $\sim 1.6$ & $\sim 1.8$ \\
\hline Power in SOL & $\mathrm{P}_{\text {sol }}(\mathrm{MW})$ & $\sim 150$ & $\sim 90$ \\
\hline Parallel Heat Flow & $q_{\|}$ & $\sim 5$ & $\sim 1.8$ \\
\hline Poloidal Heat Flow & $q_{p o l}$ & $\sim 2$ & $\sim 0.6$ \\
\hline \hline
\end{tabular}

One of the main DEMO in-vessel components is the divertor with relative plasma facing components(PFCs) [5] and [6].
The DEMO divertor will extract the alpha particle power, helium and impurities, and the heat load that comes from the plasma Scrape-Off Layer (SOL) during the normal and transient operation, and also during offnormal events. It will restrict the backflow of neutrals to prevent its Helium content become excessive.

At the same time the divertor will provide neutron shielding for the Vacuum Vessel (VV) and superconducting magnet coils.

\section{Divertor Design description}

The 2019 CAD reference for the DEMO divertor design is show in Fig. 1. The divertor is made of 48 divertor assemblies. The main divertor components are:

- $\quad$ Inboard vertical target (IVT);

- $\quad$ Outer Vertical target (OVT);

- $\quad$ Shielding Liner (SL);

- $\quad$ Reflector Plates (RP);

- Divertor Cassette (DC);

- Inner locking on VV, so-called "nose";

- $\quad$ Outer locking on VV, so-called "wishbone";

- Cooling tubes and manifolds. 


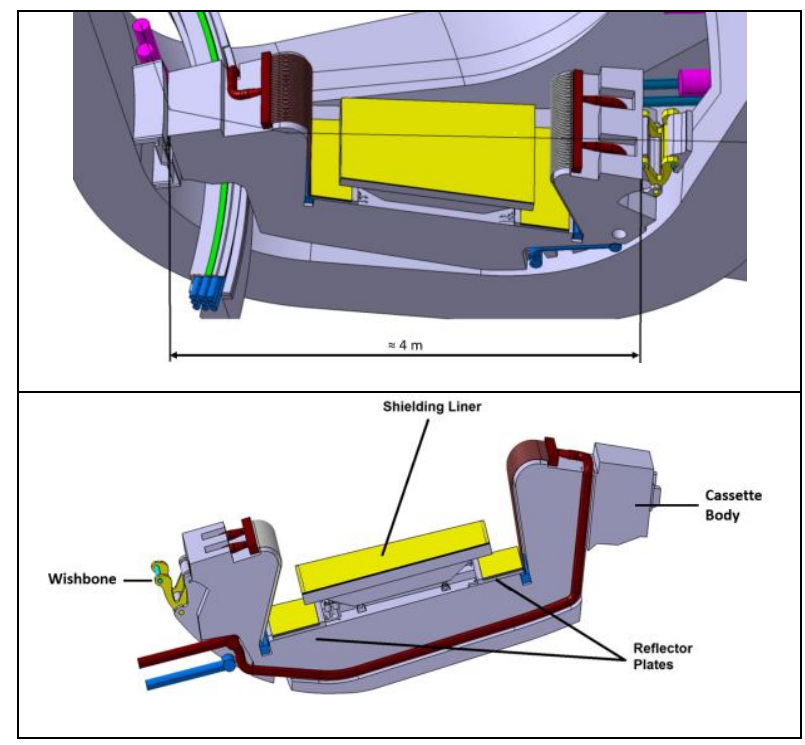

Fig. 1. CAD model of 2019 DEMO divertor assembly.

Description of the design activities for Divertor subassemblies and components are reported in [6] and [23].

\subsection{IVT and OVT}

Each cassette carries two Vertical Targets (VTs): inner (IVT) and outer (OVT). IVT is $\sim 0.76 \mathrm{~m}$ high $\mathrm{x}$ $0.82 \mathrm{~m}$ wide. OVT is $\sim 0.65 \mathrm{~m}$ high $\mathrm{x} 1.07 \mathrm{~m}$ wide. One OVT includes 45 Plasma Facing Units (PFUs) and one IVT includes 33 PFUs.

The PFUs (Fig. 2 left) are made of Tungsten (W) monoblock $(28 * 23 \mathrm{~mm}$ - axial thickness/axial gap/toroidal gap $12 \mathrm{~mm} / 0,5 \mathrm{~mm} / 0,5 \mathrm{~mm}$ ) cooled by water flowing in $\mathrm{CuCrZr}$ tubes $\left(\mathrm{D}_{\text {est }}=15 \mathrm{~mm}, \mathrm{D}_{\text {int }}=12\right.$ $\mathrm{mm}$ ). A $1 \mathrm{~mm} \mathrm{Cu}$ interlayer is foreseen between $\mathrm{W}$ and $\mathrm{CuCrZr}$. Toroidal shadow issues have not yet been taken into account, therefore the design of the monoblocs has not yet been finalized from this point of view.

The W-monoblocks are brazed to support leg (Fig. 2 right). A pin connection link the support leg to a support plug welded in the divertor cassette. The support leg, support plug and the pin are made of Eurofer (or as in ITER made in austenitic stainless-steel XM-19 -UNS number S20910).

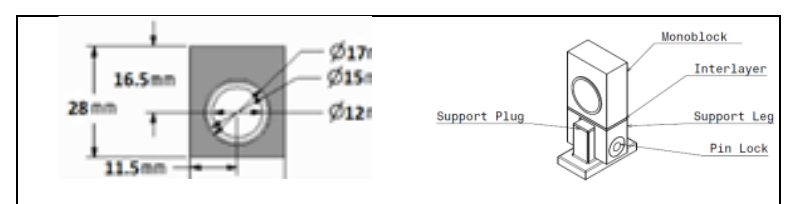

Fig. 2. ITER like PFC for DEMO divertor. left) Wmonoblok-cooling tube detail; right) PFC support.

Each PFU array has been fixed to the cassette as shown in Fig. 3 with a pitch of about $5 * 12.5=62.5 \mathrm{~mm}$ between two axial support plugs. The removal of PFCs from cassette body during maintenance activities is not currently foreseen, but the maintenance strategy is defined to replace the whole $\mathrm{CB}+\mathrm{PFCs}$ assembly after 1.5 full power year (fpy).

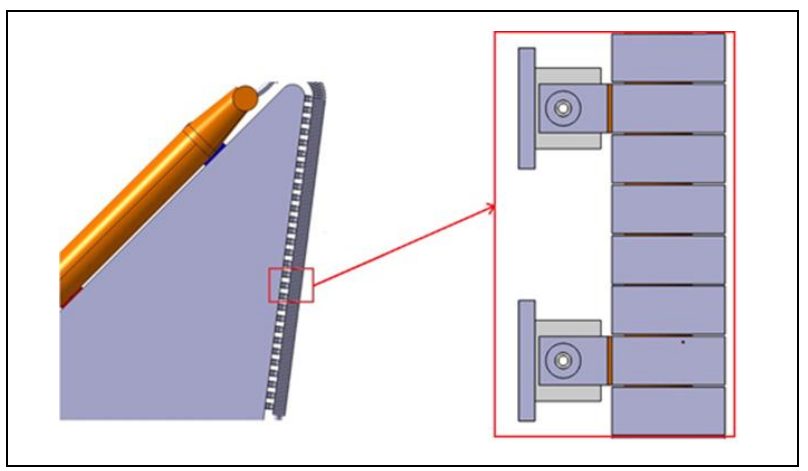

Fig. 3. PFC connection scheme on cassette divertor.

\subsection{Shielding Liner}

The main SL function is to provide neutron shielding for the VV and magnet coils. Due to the pumping opening on the cassette (Fig. 1) the neutron shielding performance is particularly important for the SL.

The SL is made of Eurofer with a first layer of $3 \mathrm{~mm}$ of tungsten and cooled by the cassette cooling circuit (Fig. 1 and Fig. 4Error! Reference source not found.).

With the collaboration of an industrial partner, a preliminary manufacturing sequence including machining, welding and NDT steps is proposed. The preliminary assessment takes into account know-how on Eurofer manufacturing and assembly technologies assessed of the ITER TBMs (Test Blanket Modules) [7],[8],[9] and [10] and the DEMO BB (Breeding Blanket) [11], [12] and [13]. Two main routes are envisaged:

- Parallel production of the cooled plates (blue and green colors in Fig. 4) and final assembly of both;

- Assembly in series by successive addition of layer.

The proposed manufacturing technology is based mainly on HIP process. For the 2-steps HIP, the cycle at low temperature in a low pressure atmosphere allow to seal the periphery of the interface before the cycle at high temperature in a high pressure atmosphere without collapsing the channels. Between the two HIP cycles, the channels are opened by drilling or milling in order to put them under pressure during the second HIP cycle. The latter allows to achieve full bonding and reach good joint mechanical properties [1].

To protect the SL steel from erosion due to impact of particles, a tungsten coating is foreseen as for the BB FW. Differences in the coefficients of thermal expansion between the $\mathrm{W}$ coating and the steel substrate of the FW can be compensated by a functionally graded interlayer. Successful production has been obtained by using vacuum plasma spraying technique to deposit a $\mathrm{W}$ layer on small Eurofer surface. Layers do not present any damage after testing its resistance to thermal fatigue (until 500 cycles at high temperature). Regarding the layer adhesion, testing at high temperature reveals a good metallurgical bonding to the substrate. Next steps will consist in checking the feasibility to produce similar quality on larger surface areas. 


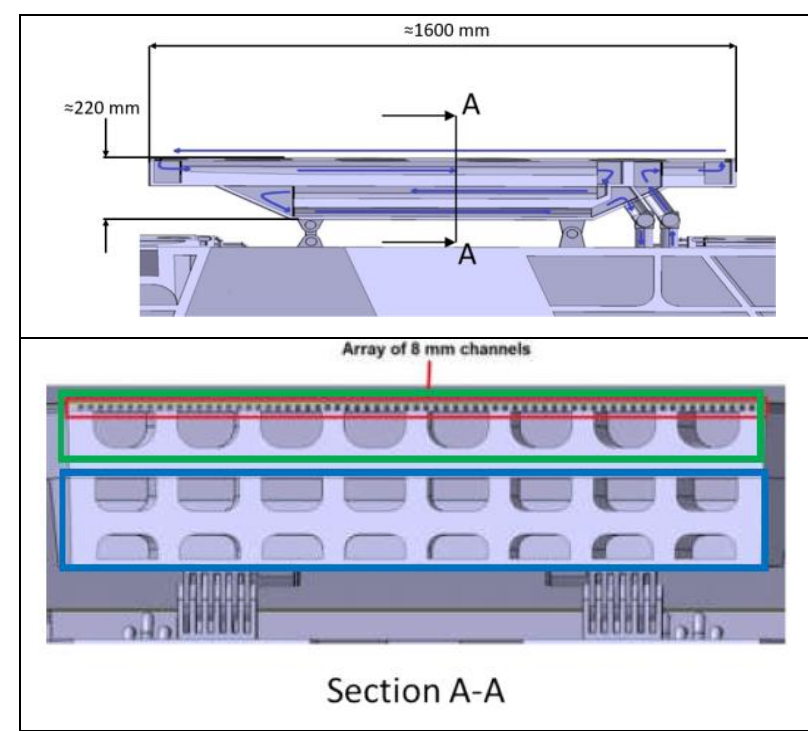

Fig. 4 - Shielding Liner

\subsection{Reflector Plates}

The main RPs functions are to provide thermal, alpha particle and impurities shielding for the PFC manifold/distributor cooling underneath components. As the SL the RPs are made of Eurofer with a first layer of 3 mm of Tungsten (Fig. 5).

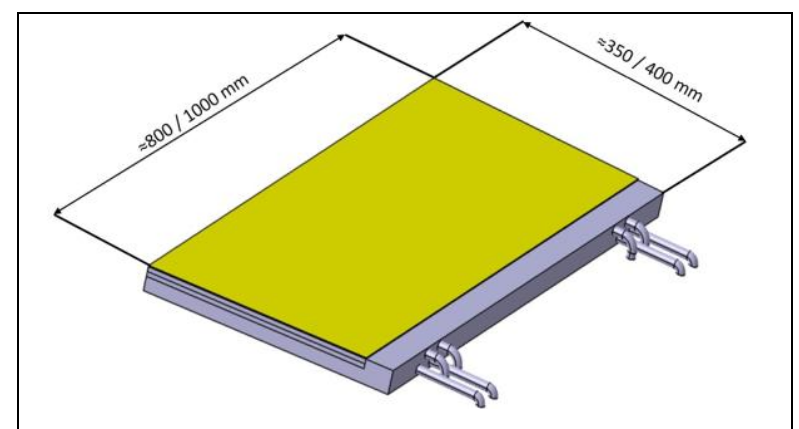

Fig. 5 -Reflector Plates

\subsection{Divertor Cassette and locking systems on VV}

The DC is an Eurofer welded structure made of two $30 \mathrm{~mm}$ external shells and internal ribs of $30 \mathrm{~mm}$ cooled with the same water circuit of liner and deflector plates (Fig. 6).

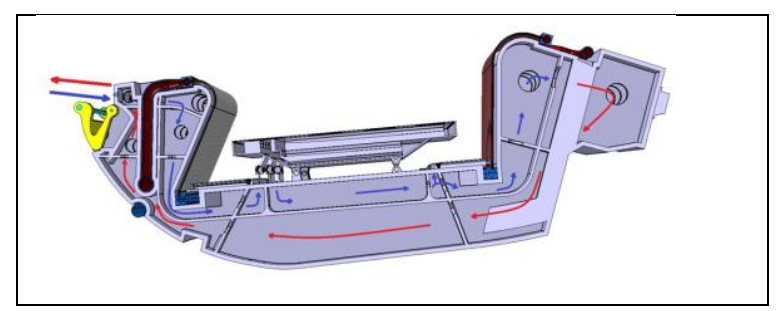

Fig. 6-Divertor assembly section with detail of cassette section and cassette cooling path.

Several solutions for fixation of $\mathrm{CB}$ to $\mathrm{VV}$ have been studied in the pre-conceptual design stage [24].

In the current design, on the inboard side the $\mathrm{DC}$ is fixed to the VV with two shear key-like structures called "nose". On the outboard a flexible component called "wishbone" (made in Ti-6Al-4V) fixes the DC via pin connections to the VV. These mechanical attachments, see Fig. 7, support the DC against all loads acting on the cassette assembly, see Table 1, Table 3 and Table 5Error! Reference source not found.

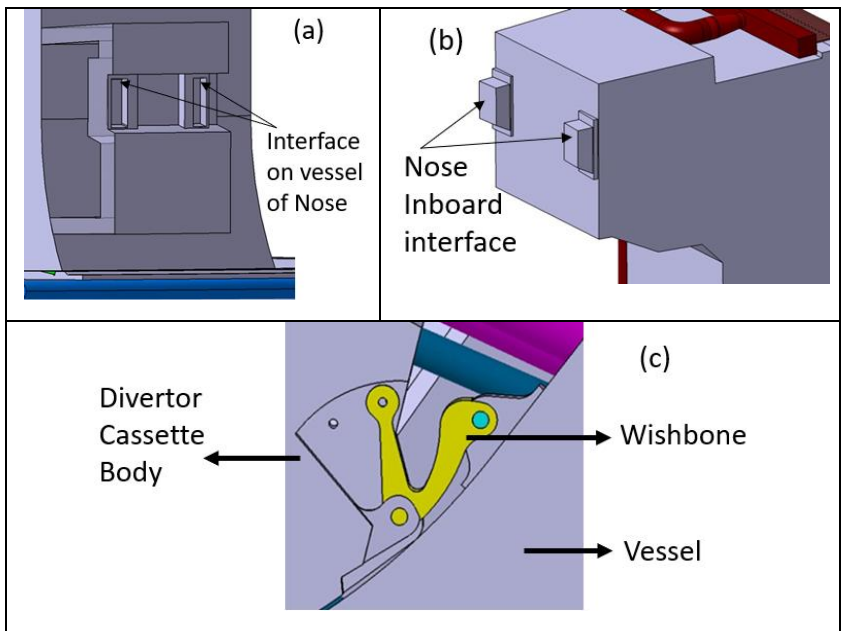

Fig. 7- Divertor Cassette and locking systems on VV a) and b) inner locking; c) outer locking system.

$12.5 \mathrm{~mm}$ of maximum differential thermal expansion in Normal Operation Condition (NOC) has been obtained by means of a thermal calculation of the DC/VV under Backing and NOC.

Fig. 8- Divertor Cassette and locking systems on VV a) and b) inner locking; c) outer locking system.

The differential thermal expansion causes a maximum radial force on the DC attachments of about 25 tons given the elastic spring constant of the Wishbone of 2 tons/mm (see Fig. 9).

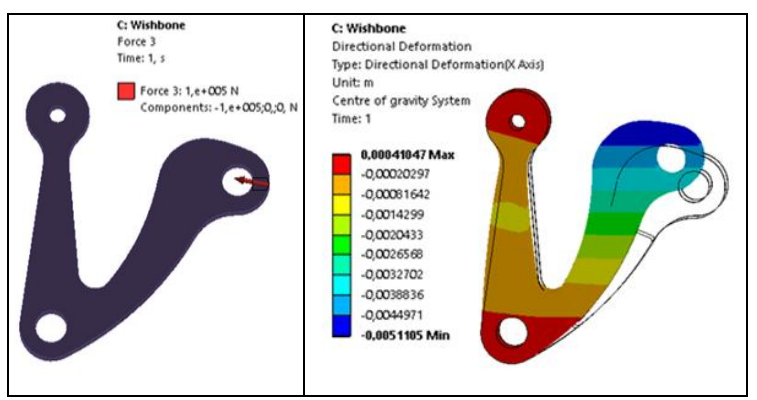

Fig. 9 -Wishbone elastic spring constant calculation: $\mathrm{K}=\mathrm{F} /$ displacement $=100000 \mathrm{~N} / 5.11 \mathrm{~mm}=19.6 \mathrm{kN} / \mathrm{mm}$ $=2$ tons $/ \mathrm{mm}$.

\section{Loads Specification and main analyses for Divertor Assembly}

The main loads considered for the DEMO divertor can be found in [15]. In the following the most important results are reported.

\subsection{Baking and NO Condition}

Baking conditions:

VV:

$$
\begin{aligned}
& \mathrm{T}=180^{\circ} \mathrm{C} \mathrm{p} \sim 2 \mathrm{MPa} \\
& \mathrm{T}=240^{\circ} \mathrm{C} \mathrm{p} \sim 4 \mathrm{MPa} \\
& \mathrm{T}=240^{\circ} \mathrm{C} \mathrm{p} \sim 4 \mathrm{MPa}
\end{aligned}
$$

DC (including SL and RPs)

Divertor PFC 
Normal Operating Conditions:

Vacuum vessel temperature:

DC (including SL and RPs) $\mathrm{T}_{\text {inlet }}=180^{\circ} \mathrm{C} \mathrm{p}_{\text {inlet }} \sim 3.5 \mathrm{MPa}$

Divertor PFC $\quad \mathrm{T}_{\text {inlet }}=130^{\circ} \mathrm{C} \mathrm{p}_{\text {inle }} \sim 5 \mathrm{MPa}$

\subsection{Heat loads}

For thermal-hydraulic calculations, a constant value of $1.5 \mathrm{MW} / \mathrm{m}^{2}$ has been assumed as heat flux incident onto both SL and RPs plasma facing surfaces. Error! Reference source not found.Table 1 reports a preliminary evaluation of Surface Heat Load and Nuclear Volumetric Heat Load for SL, RFs and CB.

Table 2- Summary of Heat Loads considered for SLs, RP and CB.

\begin{tabular}{|c|c|c|c|c|c|}
\hline \multirow{2}{*}{ Component } & \multicolumn{3}{|c|}{ Surface Heat Load } & $\begin{array}{c}\text { Nuclear Volumetric Heat } \\
\text { Load }\end{array}$ & Total Heat Load \\
\cline { 2 - 6 } & $\begin{array}{c}\text { Plasma-Facing } \\
\text { Surface } \\
{\left[\mathrm{m}^{2}\right]}\end{array}$ & $\begin{array}{c}\text { Heat Flux } \\
{\left[\mathrm{MW} / \mathrm{m}^{2}\right]}\end{array}$ & $\begin{array}{c}\text { Power per Component } \\
{[\mathrm{MW}]}\end{array}$ & $\begin{array}{c}\text { Power per Component } \\
{[\mathrm{MW}]}\end{array}$ & $\begin{array}{c}\text { Power per Component } \\
{[\mathrm{MW}]}\end{array}$ \\
\hline SLs & 1.51 & 1.50 & 2.27 & 1.49 & 3.75 \\
\hline RP & 0.84 & 1.50 & 1.26 & 0.12 & 1.58 \\
\hline CB & 0.00 & 0.00 & 0.00 & 3.19 & 6.72 \\
\hline \multicolumn{3}{|c|}{ Total Deposited Power per Cassette [MW] } & 6.72 \\
\hline
\end{tabular}

Table 3 reports the summary for Surface Heat Load and Volumetric Heat Load for the OVT, IVT and relative piping. In order to calculate the heat power due to surface heat loads a uniform heat flux due to radiation equal to $\approx 1 \mathrm{MW} / \mathrm{m}^{2}$ and a peak heat flux at the strike point of $20 \mathrm{MW} / \mathrm{m}^{2}$ have been assumed (Fig. 10) [15].

Table 3 - Summary of Heat Load considered for Divertor OVT, IVT and Piping.

\begin{tabular}{|c|c|c|c|c|c|c|}
\hline \multirow[b]{2}{*}{ Component } & \multicolumn{4}{|c|}{ Surface Heat Load } & \multirow{2}{*}{$\begin{array}{c}\text { Nuclear volumetric } \\
\text { Heat Load } \\
\text { Power per } \\
\text { Component } \\
{[\mathrm{MW}]} \\
\end{array}$} & \multirow{2}{*}{$\begin{array}{c}\text { Total Heat Load } \\
\text { Power per Component } \\
{[\mathrm{MW}]}\end{array}$} \\
\hline & $\begin{array}{c}\text { Plasma-Facing } \\
\text { Surface } \\
{\left[\mathrm{m}^{2}\right]} \\
\end{array}$ & $\begin{array}{l}\text { Peak Heat } \\
\text { Flux } \\
{\left[\mathrm{MW} / \mathrm{m}^{2}\right]}\end{array}$ & $\begin{array}{l}\text { Background } \\
\text { Heat Flux } \\
{\left[\mathrm{MW} / \mathrm{m}^{2}\right]} \\
\end{array}$ & $\begin{array}{c}\text { Power per } \\
\text { Component } \\
{[\mathrm{MW}]} \\
\end{array}$ & & \\
\hline OVT & 0.62 & 20.0 & 0.98 & 1.38 & \multirow{2}{*}{0.34} & \multirow{2}{*}{2.76} \\
\hline IVT & 0.49 & 20.0 & 0.98 & 1.04 & & \\
\hline Piping & 0.00 & 0.0 & 0.00 & 0.00 & 0.12 & 0.12 \\
\hline \multicolumn{4}{|l|}{ TOTAL } & 2.42 & 0.46 & 2.88 \\
\hline \multicolumn{6}{|c|}{ Total Deposited Power per Cassette [MW] } & 2.88 \\
\hline \multicolumn{6}{|c|}{ Total Deposited Power per 48 Cassette [MW] } & 138 \\
\hline
\end{tabular}

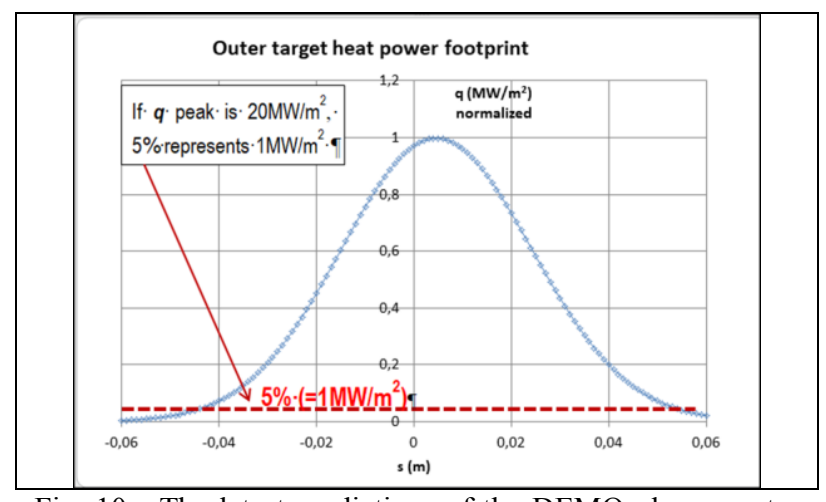

Fig. 10 - The latest predictions of the DEMO plasma outer target heat flux footprint indicate an exponential distribution that, scaling to the worst case scenario considered, can be represented by a transient partial loss of detachment with a peak heat flux of $20 \mathrm{MW} / \mathrm{m}^{2}$, and considering as high heat flux (HHF) the region that remains above $1 \mathrm{MW} / \mathrm{m}^{2}[15]$.

\subsection{Neutronics calculations}

Neutronics calculations for the DEMO divertor 2019 configuration, reported in Fig. 1, are in progress. For the present assessment the volumetric nuclear heating value results calculated in 2018 [15] [16] have been used and extrapolated to the 2019 configuration.

Error! Reference source not found. and Table 3). Fig. 11 shows the 2018 neutronics models.

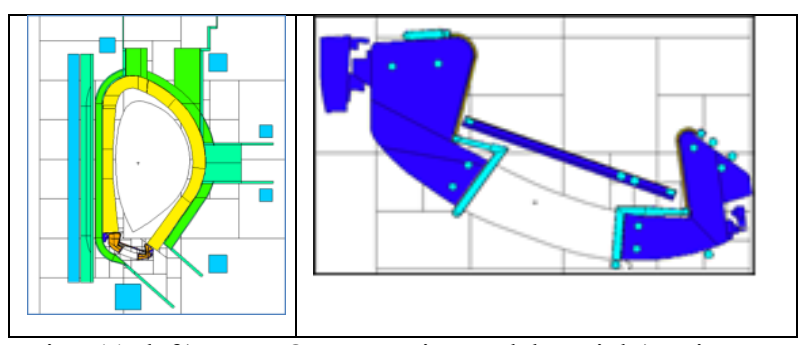

Fig. 11 left) DEMO neutronic model; right) Divertor Cassette model 
The nuclear quantities calculated in the divertor neutronics analyses are as follows [16]:

-Spatial distribution of neutron flux $\left(\mathrm{n} / \mathrm{cm}^{2} / \mathrm{s}\right)$;

-Total nuclear power and breakdown in each component $(\mathrm{kW})$;

-Spatial distribution of nuclear heating density $\left(\mathrm{W} / \mathrm{cm}^{3}\right)$ in all divertor components (IVT, OVT, SLs, DP, CB and supports);

-Maps of Nuclear heating density $\left(\mathrm{W} / \mathrm{cm}^{3}\right)$ used as input for thermal analyses;

-Spatial distribution and damage (Dpa/full power year (FPY), for Eurofer, $\mathrm{Cu}$ and W;

- Spatial distribution of He-production (appm/FPY,) in Eurofer, $\mathrm{Cu}$ and $\mathrm{W}$;

-Evaluation of the shielding performances of SL, DPs and $\mathrm{CB}$;

-Impact on $\mathrm{CB}$ and SL on SL and CB supports of nuclear heating and damage.

The maximum values of the neutron damage in divertor and VV are reported in Table 4.

Table 4 Maximum neutron damage (dpa) on Divertor (components/materials layers) and Vacuum Vessel.

\begin{tabular}{|l|c|c|}
\hline \multicolumn{1}{|c|}{ Material/Layer } & Dpa/FPY & Dpa /(2 FPY) \\
\hline W/ PFC- Ist layer & 1.98 & 3.96 \\
\hline W/ Liner- Ist layer & 1.76 & 3.52 \\
\hline Cu /PFC- IIIrd layer & 7.14 & 14.3 \\
\hline Eurofer /PFC-supports & 4.38 & 8.77 \\
\hline Eurofer /Liner- II layer & 4.91 & 9.82 \\
\hline & Dpa/FPY & Dpa /(6 FPY) \\
\hline AISI 316 L(N) - VV layer & $\sim 0.55$ & $\sim 3.3$ \\
\hline
\end{tabular}

In particular the neutronics analyses showed some critical issues related to the lack of fulfillment of design criteria for the divertor and VV:

- Cumulated damage (dpa) in Eurofer: in order to limit the material properties degradation under low temperature irradiation $\left(<180^{\circ} \mathrm{C}\right)$, the damage on Eurofer shall be below of 6 dpa over its lifetime here assumed to be 2 FPY [17].

- Cumulated damage (dpa) on $V V$ : a maximum damage of 2.75 dpa over 6 FPY have been fixed for AISI $316 \mathrm{~L}(\mathrm{~N})$ IG in order to have negligible irradiation damages in temperature range of 20 to $375^{\circ} \mathrm{C}$ [14].

A possible solution for these issues can be to reduce the lifetime of Cassette from 2 to 1.22 FPY. The possibility of increasing the neutron shielding performance of the CB/SL system in the 2019 design (Fig. 1) is also under evaluation in order to increase the lifetime of the VV.

\subsection{Thermo-Hydraulic analysis}

The cooling scheme of the DEMO divertor consists of two separate cooling circuits. One is for all Divertor Eurofer components as CB, SP and RPs with $\mathrm{p}_{\text {inlet }} / \mathrm{T}_{\text {inlet }}=$ $3.5 \mathrm{MPa} / 180{ }^{\circ} \mathrm{C}[18]$ and the other one is for PFCs with $\mathrm{p}_{\text {inlet }} / \mathrm{T}_{\text {inlet }}=5 \mathrm{MPa} / 130{ }^{\circ} \mathrm{C}[19]$.

For the thermal-hydraulic analysis the principal inputs are obtained from plasma surface heating and volumetric neutron heating (see $\S 4.2$ ). The main design limits that should be taken under control are:

1) Divertor Cassette cooling circuit (Fig. 12):

- $\quad$ Maximum Temperature on the Eurofer $<550{ }^{\circ} \mathrm{C}$;

- Maximum water pressure drop < 1.4 MPa;

- Margin against water saturation temperature $>20^{\circ} \mathrm{C}$

2) Plasma Facing cooling circuit (Fig. 13):

- Maximum water velocity in PFC tubes $<16 \mathrm{~m} / \mathrm{s}$

- CHF margin > 1.4;

- Maximum pressure drop $<1.4 \mathrm{MPa}$;

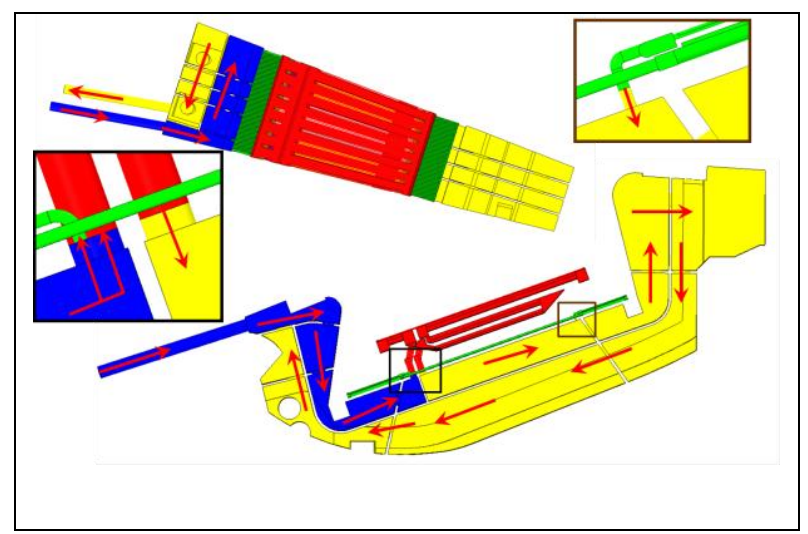

Fig. 12 - Cooling circuit of CB, RPs and SL.

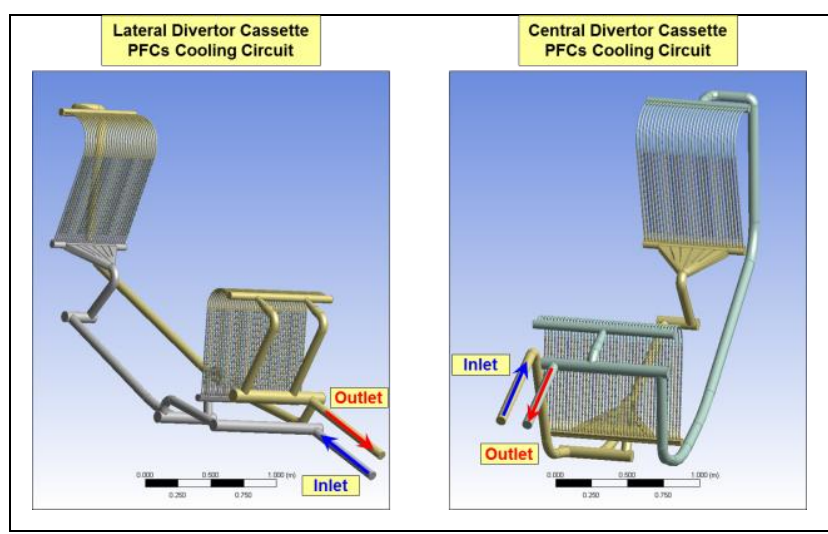

Fig. 13 - PFCs Cooling circuit layout.

A physical mock-up of the OVT for the verification of the thermo-hydraulic performances has been designed [25] and it is currently under testing.

\subsection{Electromagnetic(EM) analysis}

The EM loads are the most important mechanical loads on the divertor components and in particular for the supports design (e.g. cassette, PF, SP and DPs 
supports). In [15],[20] and [21] the following divertor relevant EM conditions have been studied:

- Vertical Displacement Event Upward with a linear Current Quench of 74ms duration (VDEUP_74msLCQ)

- Toroidal Field Magnet Fast Discharge (TFC- MFD): a total TFC exponential current decay of $27 \mathrm{~ms}$ time constant is assumed;
Future work will taking into account the other EM load as downward VDEs or disruptions and also halo current effect.

The EM resultants (forces and moments) on the divertor assembly are reported in Table 5Error! Reference source not found. An important load is the "Maxwell force on Ferromagnetic material" due to the magnetic influence of magnetic toroidal field on the Eurofer parts of the divertor assembly.

Table 5 - EM Force and Moment on Divertor assembly

\begin{tabular}{|c|c|c|c|c|c|c|c|}
\hline & $\begin{array}{l}\text { Maxwell } \\
\text { loads on } \\
\text { Ferromagnet } \\
\text { ic material }\end{array}$ & $\begin{array}{c}\text { VDEUP } \\
\text { (74msLCQ) }\end{array}$ & $\begin{array}{l}\text { TFC- } \\
\text { MFD }\end{array}$ & & $\begin{array}{c}\text { Maxwell } \\
\text { loads on } \\
\text { Ferromagnet } \\
\text { ic material } \\
\end{array}$ & $\begin{array}{c}\text { VDEUP } \\
(74 \mathrm{~ms} \\
\text { LCQ) }\end{array}$ & $\begin{array}{l}\text { TFC- } \\
\text { MFD }\end{array}$ \\
\hline $\begin{array}{c}\text { Frad }(\mathrm{kN}) \\
\text { (max outward) }\end{array}$ & 0 & 450 & 0 & $\begin{array}{l}\text { Mrad }(\mathrm{kNm}) \\
\text { (max outward) }\end{array}$ & 0 & 1000 & 0 \\
\hline $\begin{array}{c}\text { Frad (kN) } \\
\text { (max inward) }\end{array}$ & -800 & -150 & -650 & $\begin{array}{l}\text { Mrad (kNm) } \\
\text { (max inward) }\end{array}$ & 0 & -900 & -60 \\
\hline $\begin{array}{l}\text { Ftor }(\mathrm{kN}) \\
(\max \\
\text { outcoming) }\end{array}$ & 0 & 400 & 0 & $\begin{array}{l}\text { Mtor }(\mathrm{kNm}) \\
(\max \\
\text { outcoming) }\end{array}$ & 0 & 100 & 380 \\
\hline $\begin{array}{c}\text { Ftor (kN) } \\
\text { (max incoming) }\end{array}$ & 0 & -400 & 0 & $\begin{array}{l}\text { Mtor }(\mathrm{kNm}) \\
(\max \\
\text { incoming })\end{array}$ & 0 & -400 & 0 \\
\hline $\begin{array}{c}\text { Fver }(\mathrm{kN}) \\
\text { (max upward) }\end{array}$ & 0 & 1300 & -500 & $\begin{array}{l}\text { Mver (kNm) } \\
\text { (max upward) }\end{array}$ & 0 & 2400 & 0 \\
\hline $\begin{array}{c}\text { Fver }(\mathrm{kN}) \\
(\max \\
\text { downward })\end{array}$ & 0 & -400 & -1500 & $\begin{array}{l}\text { Mver }(\mathrm{kNm}) \\
(\max \\
\text { downward })\end{array}$ & 0 & -2700 & -2800 \\
\hline
\end{tabular}

\section{Conclusion}

A complete overview of the main design activities of the DEMO divertor have been presented together with the most relevant loads. Critical issues under study have been also pointed out, as for example, the damage on the materials of the divertor cassette (Eurofer) and on VV (AISI 316-L(N)-IG).

\section{Acknowledgments}

This work has been carried out within the framework of the EUROfusion Consortium and has received funding from the Euratom research and training programme 2014-2018 and 2019-2020 under grant agreement No 633053. The views and opinions expressed herein do not necessarily reflect those of the European Commission.

\section{References}

[2] F. Romanelli, P. Barabaschi, D. Borba, G. Federici, L. Horton, R. Neu, D. Stork and H. Zohm - Fusion Electricity: a roadmap to the realisation of fusion energy, EFDA 2012- ISBN 978-3-00040720-8

[3] Tony Donné, William Morris - European Research Roadmap to the Realisation Fusion Energy, EUROfusion Programme Management - November 2018 - ISBN 978-3-00-061152-0.

[4] G. Federici et al - Overview of the DEMO staged design approach in Europe, Nuclear Fusion 59 (2019) 066013 (25pp)
[5] J.H. You, G. Mazzone et al., Conceptual design studies for the European DEMO divertor: Rationale and first results, Fusion Engineering and Design, Volumes 109-111, Part B, 2016,Pages 1598-1603.

[6] J.H. You, G. Mazzone et al., Progress in the initial design activities for the European DEMO divertor: Subproject "Cassette", Fusion Engineering and Design, Volume 124, 2017, Pages 364-370.

[6] Marzullo, D., Bachmann, C., Coccorese, D., Di Gironimo, G., Mazzone, G., \& You, J. H. (2017). Systems engineering approach for pre-conceptual design of DEMO divertor cassette. Fusion Engineering and Design, 124, 649-654.

[7] Zmitko, M. and al. The European ITER Test Blanket Modules: Current status of fabrication technologies development and a way forward. Fusion Engineering and Design. 2015, pp. 199-207.

[8] Zmitko, M. and al. The European ITER Test Blanket Modules: EUROFER97 material and TBM's fabrication technologies development and qualification. Fusion Engineering and Design. 2017, Vol. 124, pp. 767-773.

[9] Forest, L. and al. The European ITER Test Blanket Modules: Fabrication R\&D progress for HCLL and HCPB. Fusion Engineering and Design. 2018, Vol. 136, pp. 1408-1416.

[10] Doyen, O. and al. Assessment of HCLL-TBM optimum welding sequence scenario to minimize welding distortions. Fusion Engineering and Design. 2017, Vol. 121, pp. 80-86. 
[11] Forest, L. and al. Status of the EU DEMO breeding blanket manufacturing R\&D activities. Fusion Engineering and Design, in review. 2018.

[12] Qu, D. and al. Development of Functionally Graded Tungsten/EUROFER Coating System for First Wall Application. Fusion Sci. Technol. 68, 2015, Vol. 3, pp. 578-581.

[13] Qu, D., Basuki, W. and Aktaa, J. Numerical assessment of functionally graded tungsten/EUROFER coating system for first wall applications. Fusion Eng. Des. 2015, Vols. 98-99, pp. 13891393.

[14] ITER SDC-IC -ITER Structural Design Criteria in-vessel components - Appendix A Materials Design Limit Data.

[15] P. Frosi et al. - DIV-1-T005-D005 WP 2018 Loads Specification (LS) for Divertor Cassette 2018 (EFDA_D_2NLWLE v1.0).

[16] R. Villari et al., WPDIV 2018 Summary: Neutronics Analysis- Annex to DIV-1-T005-D005 Loads Specification [EFDA_2NLWLE]

[17] G. Mazzone et al., Choice of a low operating temperature for the DEMO EUROFER97 divertor cassette - Fusion Engineering and Design 124 (2017) 655-658

[18] P.A. Di Maio et al., Thermal-hydraulic optimisation of the DEMO divertor cassette body cooling circuit equipped with a liner, Fusion Engineering and Design 146 Part A (2019) 220-223. https://doi.org/10.1016/j.fusengdes.2018.12.024

[19] P.A. Di Maio et al., Hydraulic analysis of EU-DEMO divertor plasma facing components cooling circuit under nominal operating scenarios, Fusion Engineering and Design, article in press. https://doi.org/10.1016/j.fusengdes.2019.03.030

[20] M. Roccella - DEMO baseline 2018 EM analysis -EM DGM including TFCs and EM analyses of Plasma disruptions plus TFCs FD [EFDA_D_2MBYNY].

[21] I. A. Maione - Maxwell force on divertor cassette - Private communication 14/03/2017.

[22] D. Marzullo et al, Structural Analysis on EU-DEMO Divertor Cassette Attachments Subjected to Thermal and Electric-magnetic Load, this conference.

[23] (Private Communication) DIV-1-T005-D008-AWP 2017Preliminary assessment of manufacturing techniques for divertor Shielding Liner Components, 2NEJJM, L. Forest.

[23] Marzullo, D., Bachmann, C., Coccorese, D., Di Gironimo, G., Frosi, P., Mazzone, G., \& You, J. H. (2019). Progress in the pre-conceptual CAD engineering of European DEMO divertor cassette. Fusion Engineering and Design, 146, 942-945.

[24] Marzullo, D., Di Gironimo, G., Lanzotti, A., Mazzone, G., \& Mozzillo, R. (2015). Design progress of the DEMO divertor locking system according to IPADeP methodology. Procedia Cirp, 34, 56-63.

[25] Mazzone, G., et al. "Structural verification and manufacturing procedures of the cooling system, for DEMO divertor target (OVT)." Fusion Engineering and Design 146 (2019): 1610-1614. 